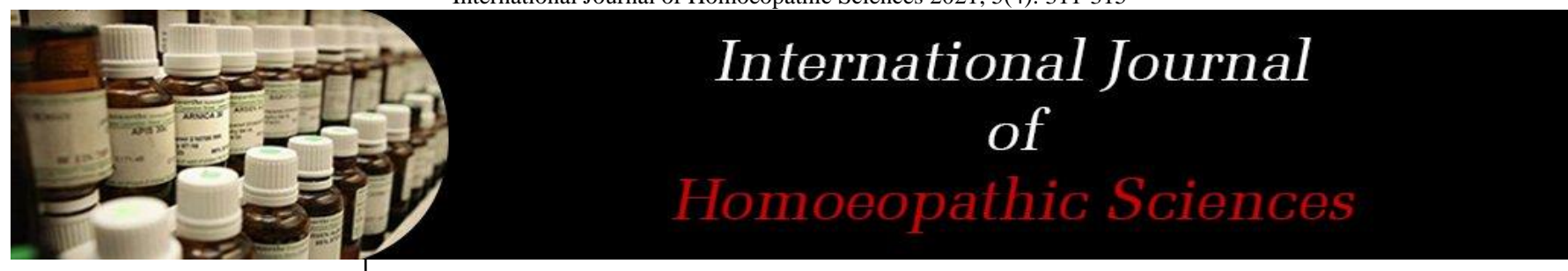

E-ISSN: $2616-4493$

P-ISSN: 2616-4485

www.homoeopathicjournal.com

IJHS 2021; 5(4): 311-315

Received: 16-08-2021

Accepted: 18-09-2021

Dr. J Senthilkumar B

Professor, Department of

Repertory, Vinayaka Mission's

Homoeopathic Medical College

\& Hospital, A Constituent

college of VMRF-Deemed to be

University, Salem,

Tamil Nadu, India

Dr. Blessy Chacko

Post Graduate Student,

Department of Repertory,

Vinayaka Mission's

Homoeopathic Medical College

\& Hospital, Salem,

Tamil Nadu, India
Corresponding Author:

Dr. Blessy Chacko

Post Graduate Student,

Department of Repertory,

Vinayaka Mission's

Homoeopathic Medical College

\& Hospital, Salem,

Tamil Nadu, India

\section{Efficacy of homeopathic medicine in treatment of polycystic ovarian syndrome using Kent repertory}

\section{Dr. J Senthilkumar and Dr. Blessy Chacko}

DOI: https://doi.org/10.33545/26164485.2021.v5.i4e.490

\section{Abstract}

An endocrine disorder known as polycystic ovarian syndrome (PCOS) that affects about 10 million people in the world. Current incidence of PCOS (5-6\%) is fast increasing latterly due to change in the lifestyle and stress.

The exact cause is unknown, but it is considered a hormonal problem. It is a leading cause of female infertility and it is responsible for a number of symptoms that can affect the body physically and emotionally.

Keywords: polycystic ovarian syndrome, homoeopathic management, Kent repertory

\section{Introduction}

Polycystic ovarian syndrome is a heterogeneous multisystem endocrinopathy in women of reproductive age with the ovarian manifestation of multiple metabolic disorders and broad variety of clinical characteristics, such as, menstrual abnormality, obesity and hyperandrogenism. Named as Stein-Leventhal syndrome in $1935^{[1]}$.

Polycystic ovarian syndrome is a heterogeneous disorder which is characterized by increased production of androgen in ovaries ${ }^{[2]}$.

\section{Incidence and Prevalence}

Due to changes in the lifestyle and stress, the current incidence of PCOS (5-6\%) is increasingly rising lately. It is a common problem that develops soon after puberty among adolescents ${ }^{[1]}$.

Polycystic ovarian syndrome's prevalence is generally estimated in the range of $3 \%$ to $10 \%$ but according to ethnicity and geographical location it is usually unknown for specific subpopulations ${ }^{[3]}$.

The polycystic ovarian syndrome prevalence in India ranged from about three to twenty-two percentage depending on the study population ${ }^{[4]}$. The studies were conducted in Tamil Nadu revealed the prevalence of PCOS as $18 \%$ (by using Rotterdam's criteria), were in Maharashtra and south India ranged from $9 \%$ and $22 \%$ and $10.7 \%$ by (Androgen Excess Society criteria) respectively ${ }^{[5]}$.

\section{Polycystic Ovarian Syndrome}

PCOS has been arguably identified as one of the most regular endocrinopathy amongst the reproductive age grouped women, affecting $5 \%$ to $10 \%$ of the women worldwide. It is characterized by anovulation with a chronic nature, either clinical or biochemical hyperandrogenism, and polycystic ovaries. Gynaecologists from America, Dr. IRVING F stein and Dr. Michael 1 leventhal gave the primary or foremost description about the syndrome in 1935 associated with the presence of ovarian cysts with anovulation.

It is known to be a life style disease condition. It is closely related to tissue level insulin resistance- related metabolic syndrome, with resulting hyperinsulimia. It affects a large percentage of women.

\section{Aetiology}

Several causes have been attributed to polycystic ovarian syndrome, including stress, life style changes and diet. Initially the changes can see in the ovary in the endocrine pattern ${ }^{[1]}$.

Genetic factor ${ }^{[6]}$.

Candidate genes in pcos ${ }^{[7]}$. 
Familial environment factor ${ }^{[1]}$.

Stress ${ }^{[8]}$.

Obesity ${ }^{[9]}$.

Insulin resitance resulting in hyperinsulinemia ${ }^{[9]}$.

Abnormal lipoproteins are common in pcos

- Elevated level of total cholesterol and LDL

- low level of HDL and apoprotein A-I

- According to one report, decreased HDL level is the most characteristics lipid alterations ${ }^{[9]}$.

Diet- binge eating and $\operatorname{pcos}{ }^{[10]}$.

Hyperandrogenism

Metabolic imbalances- insulin resistance

Psychological factor ${ }^{[10]}$.

\section{Pathology}

Macroscopically, both ovaries are enlarged a thick capsule of tunica albuginea is shown in the ovary. There is a chance for lobulated ovarian surface but the adhesions may be free from the peripheral surface. Several cysts (12 or more) 2-9 $\mathrm{mm}$ in size are found peripherally along the ovary surface, giving it an ultrasound necklace appearance. These are the atretic follicles which persist. The hyperplasia of theca cells and stromal hyperplasia accounts for an increase in the ovary size of more than $10 \mathrm{~cm}^{3}$ in volume ${ }^{[1]}$.

\section{Clinical Features}

- Menstrual Irregularities

Oligomenorrhoea

Amenorrhoea

Irregular cycles ${ }^{[1]}$.

Dysfunctional uterine bleeding ${ }^{[6]}$.

- Infertility

- Hyperandrogenism ${ }^{[1]}$.

Hirsutism

Acne ${ }^{[1]}$.

Androgenic alopecia

- Central obesity

$\mathrm{BMI}>30 \mathrm{~kg} / \mathrm{cm}^{2}$

Waist line $>35^{1}$

- Acanthosis nigricans -Condition in which the specific skin changes are due to insulin resistance. Commonly seen in the nape of the neck, groin, axilla and Inner thighs ${ }^{[2]}$.

- HAIR-AN Syndrome consist of Insulin resistance and Acanthosis nigricans and Hyperandrogenism.

- Virilism is rare.

- Recurrent spontaneous abortion

- Sleep apnea

\section{Diagnosis}

Rotterdam criteria, Diagnosis are based upon the presence of any 2 of the following 3 criteria. [American society for reproductive medicine (ASRM)/ European society for the human reproductive embryology (ESHRE) 2003].

- Oligomenorrhoea /amenorrhoea, anovulation, infertility

- Hyperandrogenism (clinical / biochemical)

- Ultrasound findings ${ }^{[2]}$.

\section{Aims and objectives}

- To study the efficacy of homeopathic medicine in the management and treatment of polycystic ovarian syndrome.

- To know the utility of Kent repertory in polycystic ovarian syndrome.

\section{Materials and Methods}

Source of data:

The subjects were collected from the Inpatient department (IPD) /Outpatient department (OPD) and Rural Medical camps conducted and Peripheral Health Centers, by Vinayaka Mission's Homoeopathic Medical College \& Hospital, Salem.

The literature is collected from various authentic medical and Homoeopathic books.

\section{Method of collection of data \\ Inclusion Criteria}

- Female patient of age group between 20 - 35 years were selected for this study.

\section{Exclusion Criteria}

- Patients with any congenital anomaly, Patients under other systemic diseases with major complications.

\section{Treatment plan}

The patient were assessed, analysed and evaluated according to Dr. J. T. Kent's method.

Repertorization was done using Kent's Repertory. Miasmatic Interpretation was done by using presenting complaints, past history, family history, mental and physical generals. Mental and physical generals and characteristic particulars were considered for the selection of remedy.

Criteria for the follow up were mental, physical generals and characteristic particulars

\section{Observations and results}

The purpose of this study is to know the efficacy of homeopathic medicine in the management and treatment of polycystic ovarian syndrome using Repertory of homeopathic Materia medica. The present study was performed with 30 patients diagnosed with PCOS based on the diagnostic criteria (Rotterdam criteria). The cases were taken using predesigned homeopathic case Proforma. The age of the female patient selected as the sample ranges from 20 to 35 years were selected based on the inclusion and exclusion criteria and the cases were diagnosed clinically and based on the investigation findings. After the detailed case taking all the case were repertorized using Repertory of Homeopathic Materia medica by J.T Kent and based on the reportorial totality the indicated remedy was prescribed and the cases were reviewed at regular intervals for a period of 12 months.

Table 1: Age wise distribution of polycystic ovarian syndrome cases

\begin{tabular}{|c|c|c|c|}
\hline SL NO & AGE GROUP & NUMBER OF PATIENTS & PERCENTAGE \\
\hline 1 & $20-25$ & 12 & 40 \\
\hline 2 & $25-30$ & 13 & 43.33 \\
\hline 3 & $30-35$ & 5 & 16.66 \\
\hline
\end{tabular}

Table shows, Out of 30 cases, Majority $43.3 \%$ of cases comes under 25-30 years of age group, $40 \%$ of cases comes 
under 20 - 25 years of age group, Minority group comes under 30- 35 years of age group.

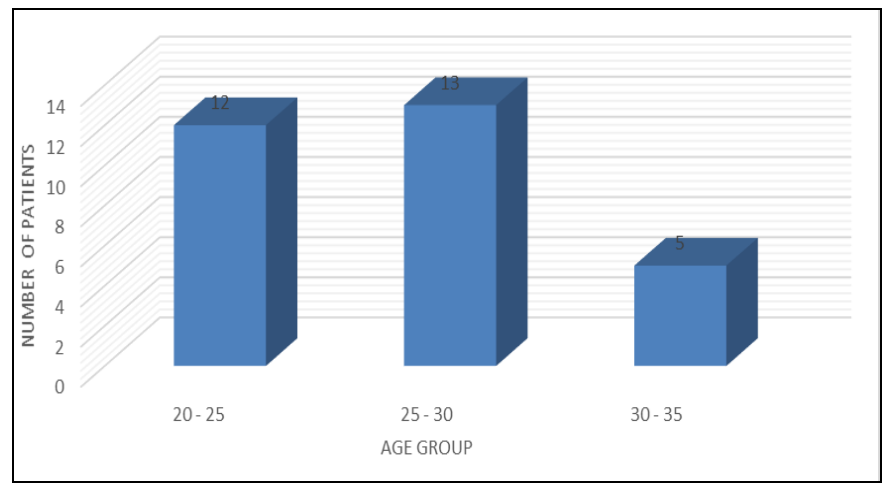

Chart 1: Age wise distribution of polycystic ovarian syndrome cases

Table 2: Distribution of PCOS cases based on occupation

\begin{tabular}{|c|c|c|c|}
\hline SL NO & OCCUPATION & NUMBER OF PATIENTS & PERCENTAGE \\
\hline 1 & STUDENT & 10 & 33.33 \\
\hline 2 & HOME MAKER & 12 & 40 \\
\hline 3 & HEALTH WORKER & 1 & 3.33 \\
\hline 5 & LECTURE & 1 & 3.33 \\
\hline 6 & BANKING PROFESSITIONAL & 3 & 10 \\
\hline 7 & TEXTILE WORKER & 2 & 3.66 \\
\hline
\end{tabular}

Table shows, In this study out of 30 cases $40 \%$ of the patients were home maker, $33.33 \%$ of cases to students, $6.66 \%$ to banking professionals, $10 \%$ to IT professitiona $1,3.33 \%$ to health workers lectures and Textile worker.

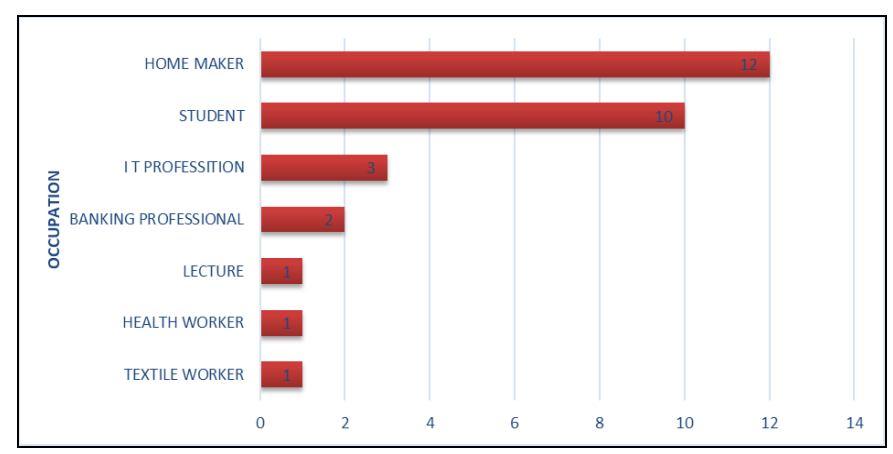

Chart 2: Distribution of PCOS cases based on occupation

Table 3: Distribution of pcos patients based on marital status

\begin{tabular}{|c|c|c|c|}
\hline SL NO & MARITAL STATUS & NUMBER OF PATIENTS & PERCENTAGE \\
\hline 1 & UN MARRIED & 10 & 33.3 \\
\hline 2 & MARRIED & 20 & 66.66 \\
\hline
\end{tabular}

Table shows, In this study out of 30 cases, PCOS is more prevalence among the married women $(66.66 \%)$ and 33.3 $\%$ of cases were in unmarried women.

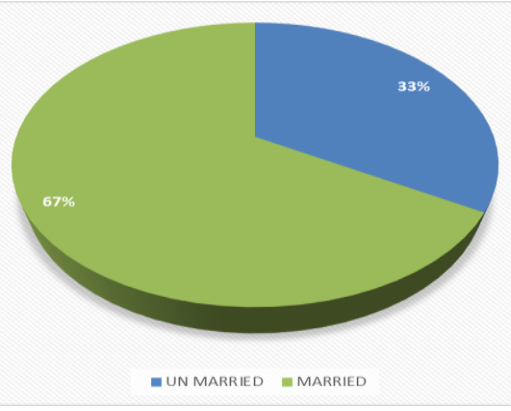

Chart 3: Distribution of PCOS patients based on marital status

Table 4: Distribution of PCOS cases based on side affection

\begin{tabular}{|c|c|c|c|}
\hline SL NO & SIDE & NUMBER OF CASES & PERCENTAGE \\
\hline 1 & UNILATERAL & 3 & 10 \\
\hline 2 & BILATERAL & 27 & 90 \\
\hline
\end{tabular}

Table shows, In this study, out of 30 cases. Most of the cases showed bilateral affection $(90 \%)$ and $10 \%$ of patients have unilateral affection.

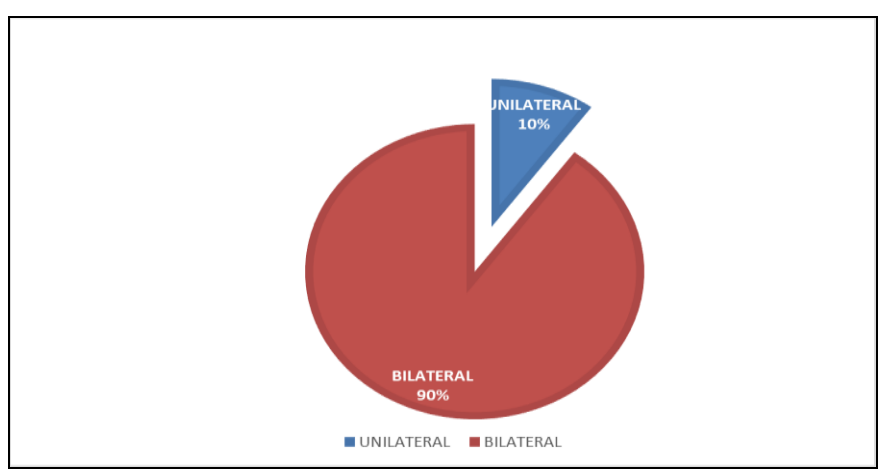

Chart 4: Distribution of PCOS cases based on side affection

Table 5: Distribution of PCOS cases based on dominant Miasm

\begin{tabular}{|c|c|c|c|}
\hline SL NO & DOMINANT MIASM & NUMBER OF CASES & PERCENTAGE \\
\hline 1 & PSORA & 0 & 0 \\
\hline 2 & SYCOSIS & 12 & 40 \\
\hline 3 & SYPHILIS & 1 & 3.33 \\
\hline 4 & PSORA - SYCOTIC & 16 & 53.33 \\
\hline 5 & SYCO - SYPHILITIC & 1 & 3.33 \\
\hline
\end{tabular}

Table shows, Out of 30 cases Majority (53.33\%) of cases have psora - sycotic as dominant miasm. $40 \%$ of cases are with sycosis as dominant miasm. $3.33 \%$ of cases comes under syphilitic and syco - syphilitic as dominant miasm.

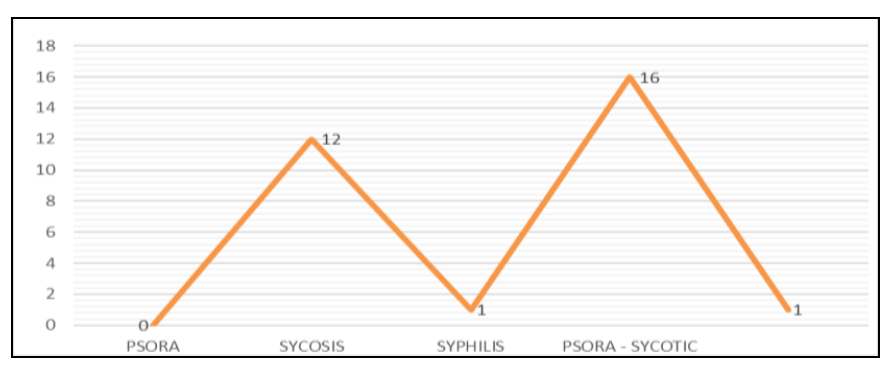

Chart 5: Distribution of PCOS cases based on dominant Miasm 
Table 6: Distribution of PCOS cases based on fundamental Miasm

\begin{tabular}{|c|c|c|c|}
\hline SL NO & FUNDAMENTAL MIASM & NO OF CASES & PERCENTAGE \\
\hline 1 & PSORA & 0 & 0 \\
\hline 2 & SYCOSIS & 19 & 63.33 \\
\hline 3 & SYPHILIS & 0 & 0 \\
\hline 4 & PSORA - SYCOTIC & 6 & 20 \\
\hline 5 & SYCO - SYPHILITIC & 5 & 16.66 \\
\hline
\end{tabular}

Table shows, After analysing the fundamental miasm of this study most of the cases have sycotic miasm (63.33\%).16.66 $\%$ of case are with syco- syphilitic miasm.20\% of cases comes under syphilitic and psoric- sycotic miasm.

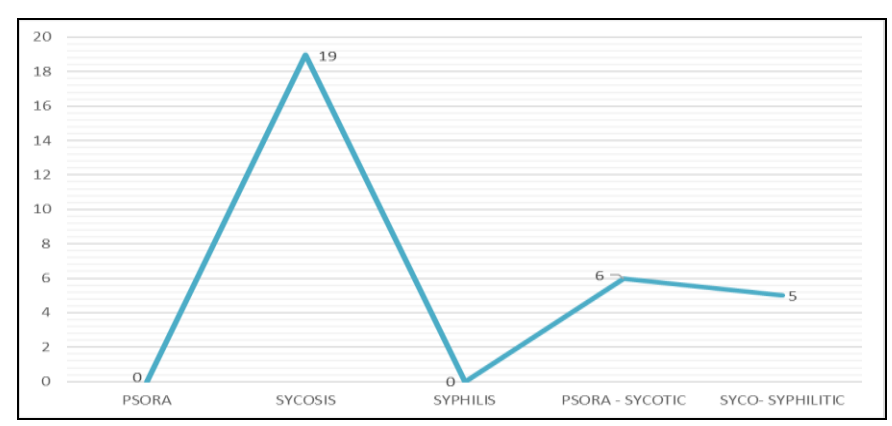

Chart 6: Distribution of PCOS cases based on fundamental Miasm

Table 7: Distribution of PCOS cases based on medicine prescription

\begin{tabular}{|c|c|c|c|}
\hline SL NO & MEDICINE PRESCRIBED & NO OF CASES & PERCENTAGE \\
\hline 1 & SEPIA OFFICINALIS & 5 & 16.66 \\
\hline 2 & LACHESIS MUTUS & 4 & 13.33 \\
\hline 3 & APIS MELLIFICA & 3 & 10 \\
\hline 4 & PULSATILLA & 3 & 10 \\
\hline 5 & NATRIUM MURIATICUM & 3 & 10 \\
\hline 6 & MEDORRHINUM & 2 & 6.66 \\
\hline 7 & CAUSTICUM & 2 & 6.66 \\
\hline 8 & PHOSPHORUS & 2 & 6.66 \\
\hline 9 & ARSENICUM ALBUM & 2 & 6.66 \\
\hline 10 & LYCOPODIUM CLAVATUM & 2 & 6.66 \\
\hline 11 & PHYTOLACCA DECANDRA & 1 & 3.33 \\
\hline 12 & SULPHUR & 1 & 3.33 \\
\hline
\end{tabular}

Table shows, In this study $16.66 \%$ of patient were prescribed with Sepia officinalis, $13.33 \%$ of cases were prescribed with Lachesis mutus, $10 \%$ of cases were prescribed with Apis mellifica, Pulsatilla and Natrum muriaticum.6.66\% of patients were prescribed with Medorrhinum, Causticum, Phosphorus, Arsenicum album and Lycopodium.3.33\% of patients were prescribed with Phytolacca and Sulphur

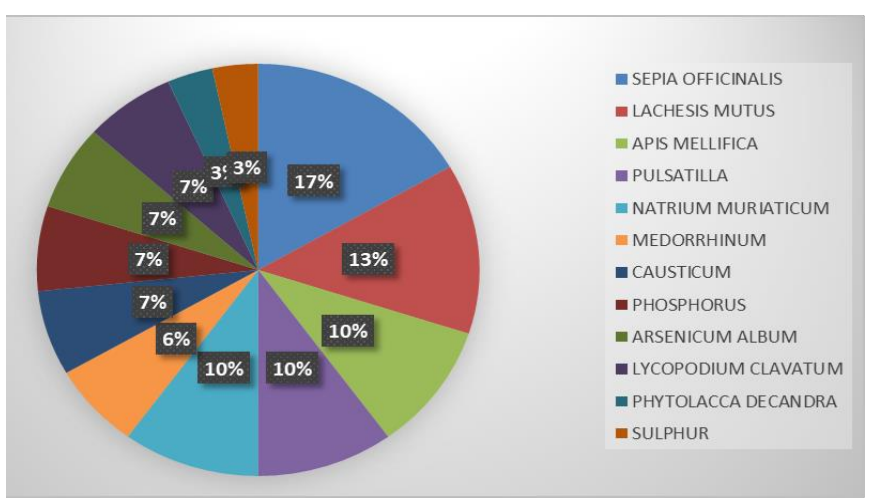

Chart 7: Distribution of PCOS cases based on medicine prescription

Table 8: Distribution of PCOS cases according to result

\begin{tabular}{|c|c|c|c|}
\hline SL.NO & RESULT & NO OF CASES & PERCENTAGE \\
\hline 1 & CURED & 10 & $33.33 \%$ \\
\hline 2 & MARKED IMPROVEMENT & 13 & $43.33 \%$ \\
\hline 3 & MODERATE IMPROVEMENT & 3 & $10 \%$ \\
\hline 4 & MILD IMPROVEMENT & 1 & $3.33 \%$ \\
\hline 5 & NO IMPROVEMENT & 3 & $10 \%$ \\
\hline
\end{tabular}

Table shows, After analysing the data $33.33 \%$ of cases are cured, $43.33 \%$ of showed marked improvement and $10 \%$ of cases showed moderate improvement $3.33 \%$ of cases showed mild improvement and $10 \%$ of cases showed no improvement.

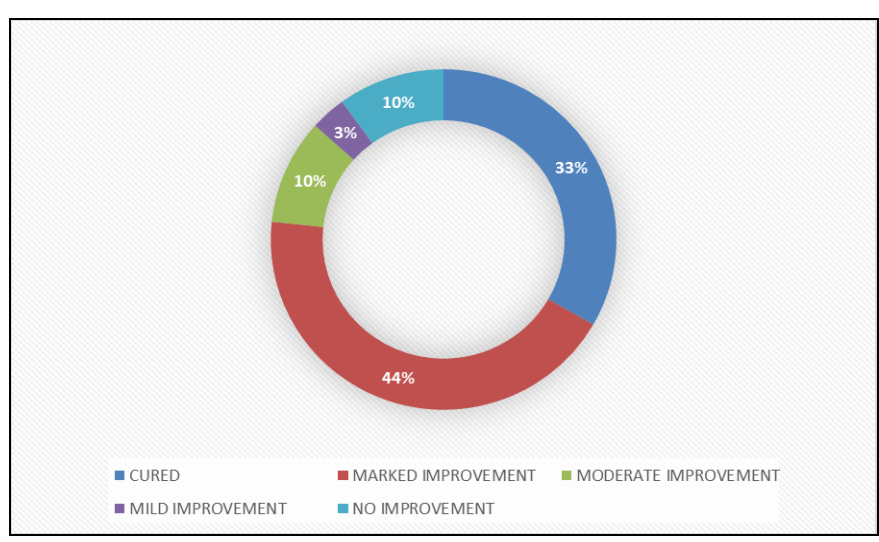

Chart 8: Distribution of PCOS cases according to result

\section{Summary and conclusion}

The study was conducted to determine the efficacy of Homeopathic medicine in treatment of polycystic Ovarian syndrome using Kent Repertory. The number of patients taken for the study was 30 . The study population of the patient were between $20-35$ years. After the detailed case taking all the case were repertorized using Repertory of Homeopathic Materia medica by J.T Kent and based on the reportorial totality the indicated remedy was prescribed in order to assess the utility of Repertory of the Homeopathic Materia Medica by J.T Kent in treating polycystic ovarian syndrome. 


\section{According to my study}

- Most of the women find out they have PCOS in between the age group of 25-30 years.

- Most of the patients affected with polycystic ovarian syndrome are married women.

- Occupational history shows more prevalence of PCOS among home makers and students. Number of students affected with PCOS is increased when compare to the previous years.

- Majority of patients having bilateral affections of ovary.

- Polycystic ovarian syndrome has predominantly Sycosis as fundamental miasm and psoric -sycotic and sycosis as dominant miasm.

- In my study majority of the patients relieved from their complaint but the secondary signs and symptoms like hirsutism, Acanthosis nigricans, obesity take long duration of time to cure.

- Stress and life style changes have a major role in the development of PCOS.

- Marked changes in the level of mental general and physical general of the patient can see during the period of treatment.

- There is no further progress and complication of disease is reported and the patient can be well managed with homeopathic medicine.

- In my cases I have used Medicines with much good effect includes Sepia, Lachesis, Apis mellifica, Pulsatila and Natrum muriaticum.

- The Kent repertory has been utilized for repertorization and showed the result of $33.33 \%$ of cases are Cured, $43.33 \%$ of showed marked improvement and $10 \%$ of cases showed moderate improvement $3.33 \%$ of cases showed mild improvement in PCOS treatment.

So, I concluded my study with the note that homeopathic medicine selected using Repertory of the Homeopathic Materia Medica by J. T Kent is effective in treatment and management of polycystic ovarian syndrome.

\section{Reference}

1. Padubidri VG, Daftary Shirish N. Howkins \& Bourne Shaws Textbook of gynaecology; 16 edition, Elsevier a division of reed Elsevier India Private limited; Harayana 2011, 431, 432.

2. Dutta DC. Textbook of Gynecology, edited by Hiralal Konar, enlarged and revised reprint of sixth edition, Jaypee Brothers Medical Publishers, private India Limited, New Delhi, 462, 459.

3. Wendy M Wolf, Rachel A Wattick, Olivia N Kinkade, Melissa D Olfert. Geographical prevalence of Poly Cystic Ovary Syndrome as determined by region and race/ethnicity, International Journal of Environmental research and Public Health 2018;15:11.

4. The Indian journal of medical research, Epidemologypathogenesis, genetic and management of polycystic ovarian syndrome in India. Wolters KluwerMedknow publications, PMCID: PMC6902362 2019;150(4):333-344

5. https://www.nhp.gov.in/disease/endocrinal/ovaries/poly cystic-ovary-syndrome-pcos

6. Prasannakumari B. Postgraduate gynaecology 1 edition, Jaypee Brothers medical publishers (p) ltd; New Delhi, 2011, 140-153.

7. PPAR Research, the genetic basis of the polycystic ovarian syndrome, A literature review including the literature review of PPAR-y, Ugur Unluturk, Ayla Harmancy, Cetin Kocaete, Bulent O Yildiz, 2007 Feb 5, volume 2007, 23-29.

8. Journal of the Human reproductive sciences, Possible link between stress related factors and altered body composition in women in Polycystic Ovarian syndrome, Barnali Ray Basu, Olivia Chowdhary and Sudip Kumar Saha 2018;11(1):10-18

9. Berek S Jonathan, Berek, Novaks gynaecology; 15 edition; Wolters Kluwer India pvt ltd 1075

10. Neuropsychiatric disease and treatment, Dove press journal, Binge eating in patients with polycystic ovary syndrome: prevalence, causes, and management strategies, Isabel Krug, Sarah Giles, Chiara Paganini,

11. Chaudhuri Snehamay, Essentials in gynaecology for undergraduate medical students, 1 edition, CBS publishers\& Distributors pvt ltd, New Delhi, 2015, 96.

12. http://www.womenshealth.gov/publications/ourpublications/fact-sheet/polycystic-ovarysyndrome.html\#c

13. http://www.pcossa.org

14. Bhasker Rao NN. Roychowdry, Clinical Gynaecology, Fifth edition, Orient Blackswan publishers, 2019,

15. Sisir, Sengupta, Thankam. Gynaecology for postgraduates and practitioners. 2 nd edition-114

16. Suvarna Khadilkar, Endocrinology in obstetrics and gynaecology, 2015, Jaypee brother's publishers private limited,newdelhi,195-200

17. http://www.healthline.com Oligomenorrhea,09-jul-2020

18. Draft summary and recommendations of international evidenced based guideline for assessment and management of Poly cystic ovary syndrome 2018

19. James Tylor Kent, AM, MD Repertory of Homeopathic Materia Medica, Sixth American Edition, Edited and Revised by Clara Louise Kent, M.D, B. Jain Publishers (p) LTD, New Delhi * 